\title{
Embodied higher cognition: insights from Merleau-Ponty's interpretation of motor intentionality
}

\author{
Jan Halák ${ }^{1}$ \\ Accepted: 26 August 2021 / Published online: 3 September 2021 \\ (C) The Author(s) 2021
}

\begin{abstract}
This paper clarifies Merleau-Ponty's original account of "higher-order" cognition as fundamentally embodied and enacted. Merleau-Ponty's philosophy inspired theories that deemphasize overlaps between conceptual knowledge and motor intentionality or, on the contrary, focus exclusively on abstract thought. In contrast, this paper explores the link between Merleau-Ponty's account of motor intentionality and his interpretations of our capacity to understand and interact productively with cultural symbolic systems. I develop my interpretation based on Merleau-Ponty's analysis of two neuropathological modifications of motor intentionality, the case of the braininjured war veteran Schneider, and a neurological disorder known as Gerstmann's syndrome. Building on my analysis of Schneider's sensorimotor compensatory performances in relation to his limitations in the domains of algebra, geometry, and language usage, I demonstrate a strong continuity between the sense of embodiment and enaction at all these levels. Based on Merleau-Ponty's interpretations, I argue that "higher-order" cognition is impaired in Schneider insofar as his injury limits his sensorimotor capacity to dynamically produce comparatively more complex differentiations of any given phenomenal structure. I then show how MerleauPonty develops and specifies his interpretation of Schneider's intellectual difficulties in relation to the ambiguous role of the body, and in particular the hand, in Gerstmann's syndrome. I explain how Merleau-Ponty defends the idea that sensorimotor and quasi-representational cognition are mutually irreducible, while maintaining that symbol-based cognition is a fundamentally enactive and embodied process.
\end{abstract}

Keywords Embodied cognition $\cdot$ Enactivism $\cdot$ Higher-order cognition $\cdot$ Motor intentionality $\cdot$ Neuropsychology $\cdot$ Phenomenology

Jan Halák

jan.halak@upol.cz

1 Faculty of Arts, Department of Philosophy, Palacký University Olomouc, Kř́žkovského 12, Olomouc 771 48, Czech Republic 


\section{Introduction: "higher-order" cognition embodied}

It would be a "deeply problematic oversight," Lawrence Hass argues (2008, 147), to pay less attention to Merleau-Ponty's interpretations of rational thought and knowledge than those of embodiment and perception. Elaborating on Hass' insight, this paper's goal is to show that Merleau-Ponty's texts contain a largely unexplored account of the sense in which our "higher-order" cognitive acts are fundamentally linked to our embodiment and motor intentionality. I argue that Merleau-Ponty's interpretation offers an important addition to current embodied-enactive theories of cognition.

Merleau-Ponty's contribution to our understanding of cognition is admittedly complex. He has inspired an influential approach to skillful embodied coping that highlights the irreducible status of unreflective motor intentionality in relation to conceptual knowledge (Dreyfus, 2002, 2005, 2007; cf. Jensen, 2009; Kelly, 2002; Mooney, 2011; Pacherie 2018). In contrast, many authors have argued that it is important not to undervalue social, cultural, and linguistic aspects of our bodily relationship to the world (e.g., Berendzen, 2010; Gallagher, 2014; 2017, 197-204; Matherne, 2018; Romdenh-Romluc, 2007, 2012). Furthermore, it is important to note that Merleau-Ponty's discussions on motor intentionality in Phenomenology of Perception must be understood as a negative rather than positive argument. MerleauPonty's point is that conceptual reflective knowledge does not constitute a necessary foundation of sensorimotor coping and perception, rather that the former is necessarily absent in the latter. ${ }^{1}$ When Merleau-Ponty eventually addresses the question positively, he clearly states that in his view, "perception is cultural-historical" and that the usage of language and abstract significations "teaches [us] to see better" (1968a, 253; 1996, 366). Consequently, in his view, a skillful linguistic expression has the power to transform our perceptual experience to "but a variant of speech before our eyes" (1968a, 155). Merleau-Ponty's account of embodiment and motor intentionality evidently needs to be interpreted considering his positively formulated views on cultural, linguistic, and conceptual aspects of cognition.

In fact, Merleau-Ponty provides a broad range of interpretations that pertain to what is currently referred to as "higher-order" levels of cognition. He inquires into the problems of "theoretical," "categorial" attitude, and "symbolic" behavior (1963, 2012, 2020a); memory and imagining (2010); linguistic expression of thought $(1964,1973,2020 \mathrm{~b})$; the constitution of ideal meaning, and quasi-universal knowledge, including mathematics (1973, 2002, 2010, 2012). Commentators have provided interpretations dedicated exclusively to these aspects of Merleau-Ponty's works (e.g., Besmer, 2007; Cassou-Noguès, 1998; Matherne, 2018; Irwin, 2017; Hass, 2008, 146-192; Romdenh-Romluc, 2011, 183-217). Beyond that, particular attention has been paid to Merleau-Ponty's appropriation of Husserl's idea of

\footnotetext{
1 Merleau-Ponty typically argues that "motor experience is not a particular case of knowledge," not that knowledge is excluded from motor experience (2012, 141). In Merleau-Ponty's view, the relationship between our practical intimacy with space and our theoretical knowledge of space "is complex" (1970, 7-8). For a detailed explanation, see below Sect. 2.2.
} 
"institution" of ideal objects and objective knowledge (e.g., Baldwin, 2013; Besmer, 2007; Hass \& Hass, 2000; Lawlor, 2002; Robert, 2000; Vallier, 2005). Merleau-Ponty's distinction between "speaking speech" and "spoken speech," which is closely related to the concept of "institution," continues to inspire studies of dynamic-enactive aspects of language in their relation to its comparatively more stable structural aspects (e.g., Cuffari, 2012; Baldwin, 2007; Kee, 2018; Kiverstein \& Rietveld, 2021; Stawarska, 2020, 117-124).

Throughout these discussions, the relationship between "higher-order" cognitive processes and embodied sensorimotor action is permanently implied. For instance, Matherne $(2018,4)$ argues against Dreyfus that Merleau-Ponty's account involves a "reciprocal relation of foundation" between perceptual and conceptual dimensions. Cuffari $(2012,614)$ appreciates Merleau-Ponty's idea that "thoughts come into being via bodily accomplishment," and similarly, Romdenh-Romluc (2011, 216) concludes that thought is "a bodily activity" for him because it is "performed or constituted by its expression." Hass $(2008,152)$ argues that mathematical knowledge involves embodiment for Merleau-Ponty because it presupposes spatially and temporally oriented perceptual fields (cf. Hass \& Hass, 2000, 179-180). Here, commentators seem to assume that "higher-order" cognition is embodied because it involves some physical exteriority or perceptual aspects. Similarly, in the discussions on Merleau-Ponty's relationship to Husserl's idea of "institution," abstract knowledge is viewed as being fundamentally embedded in a cultural situation, but the question of embodiment is present only remotely, through Husserl's idea of a presumed "materiality" of language signs (e.g., Baldwin, 2013, 314-315). In these interpretations, the general sense of embodiment presumably involved in "higherorder" cognition seems to remain weak. Embodiment is limited to providing spatiotemporal concreteness to an otherwise unmanageable and implicit thought. The role of bodily mobility clearly implied by Merleau-Ponty (e.g., 2012, 406, 408; 1970, 8) is not concretely addressed.

For Merleau-Ponty, the role of embodiment in "higher-order" cognition is clearly much stronger. Although we obviously do not think "with" specific parts of our body or by simply moving them, Merleau-Ponty argues that "we don't think without the transfigured body, [the] bearer [porteur] of significations," that is, the agent of operative motor intentionality which he calls "body schema" (2020a/2011, 121/162; cf. 118/159). ${ }^{2}$ The body in this sense is "the vehicle [porteur] of an indefinite number of symbolic systems" (1970/1968b, 9/18) because these systems "would collapse if [the body] ceases to punctuate [ponctuer] the activities we carry out in them and install them in the world and our life" (9/18; transl. modified). For Merleau-Ponty, the role of the body and its mobility in "higher-order" cognition is clearly foundational and strongly constitutive.

In a broader context, the possibility of a bodily constitution of "higher-order" cognitive acts is discussed in embodied cognition theories. Here, the relation of embodiment to cognition is often examined in terms of causality or eventually

\footnotetext{
${ }^{2}$ My interpretations sometimes build on nuances in Merleau-Ponty's original French formulations. In these cases, I refer to the pagination in the English translation/original French.
} 
compositional constitution, where a physical factor beyond the brain constitutes "a part" of a cognitive process (e.g., Clark, 2008). On the most general level, embodiment is then understood as partes extra partes physicality (e.g., Dijkerman \& Lenggenhager, 2018; Wilson \& Foglia, 2017), which is an idea that has been thoroughly criticized by Merleau-Ponty (see 1963, 3, 161, 202). ${ }^{3}$ In a Merleau-Pontyan context, the cognitive-scientific tendency to reduce cognition to a third-person process taking place within the physical world has been criticized by Pollard (2014) and Muller (2021), who contrast it with a presumed "transcendental" dimension of Merleau-Ponty's works. ${ }^{4}$ However, opposing a third-person physicality to a "transcendentality" seems to leave no room for a positive description of the role of embodiment in cognition as ultimately understood by Merleau-Ponty. An oppositional approach is vulnerable to his late (self-critical) account of embodiment as a dimension where the transcendental and empirical dimensions are originally merged and only separate by diverging from one another (cf. Morris, 2016). The late Merleau-Ponty precisely highlights that one's body is "the standard for measurement" (étalon) of the world as one of the things of the world (e.g., 2003/1995, 222-223/285). Moreover, as other commentators have pointed out, Merleau-Ponty does not just oppose philosophical descriptions to natural-scientific investigations, but rather integrates the latter into his phenomenology (Gallagher, 2010, 2018b; Reynolds, 2017; Romdenh-Romluc, 2018; Vörös, 2020).

In coherence with such an integrative approach - and often drawing on MerleauPonty himself - several embodied-enactive cognition theorists argue that embodiment is a "relational" phenomenon that involves, beyond merely physical-causal interactions, the interactions between an organism and its coupled environment (e.g., Gallagher, 2017; Thompson, 2007; Varela et al., 2016). Following a similar line of thought, Jenkinson (2017, 944-946) argues that cognitive science itself deals with experiments showing that the body must be interpreted from a distinctively MerleauPontyan relational perspective. Jenkinson (2017, 946-947) points out that studies of rubber hand illusions and immersive virtual reality experiences, for instance, show that the body involved in cognition is open to mapping itself to physical objects beyond one's individual physical body. Such an involvement of a different physical object in our bodily actions has a significant effect on our perspective on the world, rather than just causally affecting neural processes. Irwin (2017) makes a similar point in relation to "higher-order" cognition when he argues that the use of language and abstract concepts neither represents an object for a subject nor neurally re-enacts

\footnotetext{
3 The definition of embodiment is however not settled among embodied cognition theories. For discussion, see in particular Chrisley and Ziemke (2006), Di Paolo and Thompson (2014), Gallagher (2017, 27-47; 2018a), Shapiro (2019, 58-78), and Wilson and Foglia (2017). Here I disregard the debates on whether embodiment is extended beyond the brain or an individual body, and how much or little of embodiment versus representation is required for "higher-order" cognition. In my view, answering these questions does not fundamentally change their implicated assumption that embodiment is equivalent to physicality. I endorse the Merleau-Pontyan criticism of physicalism as outlined by Gallagher (2018b) and Vörös (2020).

4 Sheredos (2017) presents a similar argument, although he does not explicitly appeal to transcendentality. For discussion, see Brender (2013), Gallagher (2018b, 131-134), Inkpin (2017), and Reynolds (2017).
} 
a sensorimotor (that is, physical) event, but rather co-constitutes our enactment of our bodily "orientation" in the world.

My aim in this paper is to take up the strongest claims Merleau-Ponty formulates in support of a relational embodied-enactive approach to cognition and directly address the question of the relationship between symbol-based thought and bodily motor intentionality. More specifically, I explain Merleau-Ponty's account of "higher-order" cognition as a process of structural differentiation of the phenomenal environment operated through bodily motricity (mobilité, motricité). ${ }^{5}$ In the following two sections, I closely analyze Merleau-Ponty's interpretation of two neuropathological modifications of motor intentionality, thereby further illustrating his proximity to the interdisciplinary research typical for the cognitive science.

In section two, I take a new look at Merleau-Ponty's account of motor intentionality, which is based on the case of the brain-injured war veteran Schneider. After first summarizing the traditional interpretations of Schneider's impairment, I provide an analysis of his compensatory performances from the point of view of motor intentionality. I show that his compensations must be understood as motor attempts to increase the structuration of his phenomenal environment, and his difficulties, conversely, as a falloff into a more globally organized relationship to the world. Subsequently, I synthesize Merleau-Ponty's remarks concerning Schneider's impairments related to the domains of geometry, algebra, and language usage, and I demonstrate that, for Merleau-Ponty, there is a fundamental continuity between Schneider's difficulties and compensations in the intellectual and sensorimotor domains. Based on this, I argue that "higher-order" cognition was impaired in Schneider insofar as his injury limited his motor capacity to dynamically produce comparatively more complex differentiations of any given phenomenal structure.

In section three, I elaborate this dynamically structural account of "higher-order" cognition by building on Merleau-Ponty's working notes (2020a) relative to the neurological disorder known as Gerstmann's syndrome. I explain how, for MerleauPonty, the combination of perceptual-motor and mathematical cognitive difficulties involved in the syndrome sheds further light on the fact that the body is both a sensorimotor agent involved in practical actions and the site of a "sedimentation" of our relationship to the world, which constitutes a basis for cognitive operations of a higher order. I show how Merleau-Ponty develops and specifies his interpretation of Schneider's intellectual difficulties by describing symbol-based cognition as a "practice" of another level, yet also defends a mutually irreducible status of sensorimotor and quasi-representational cognition.

\footnotetext{
5 I note that Merleau-Ponty explicitly dismisses the interpretation according to which we would be conscious because we are mobile, in a causal sense (2020a, 110-111/151; cf. 112-113/153; 1970, 8/17).
} 


\section{Gelb and Goldstein's patient Schneider}

\subsection{Overview of Schneider's impairments}

With continued debate over the exact nature of Schneider's impairments, there is currently no agreement on how his condition should be defined from a neuropsychological standpoint. Schneider's condition was first described during the 1920s, when a series of works by Gelb and Goldstein and their colleagues deemed it a case of "psychic blindness." Correspondingly, contemporary authors usually categorize Schneider's condition as "apperceptive visual agnosia" (e.g., Farah, 2004; Jackson, 2018; Marotta and Behrmann, 2004). A reassessment during the 1940s found that Schneider largely recovered from his "blindness" and doubt was cast on the case's validity (see Goldenberg, 2003, 292-295; referring to Bay et al., 1949; Jung, 1949). However, most commentators now agree that Schneider's impairments were authentic, or at least provide a reliable source of information for a philosophical interpretation of embodiment (e.g., Farah, 2004, 22; Jensen, 2009, 373; Mooney, 2011, 361; Pacherie 2018, 370 n1; see also Dreyfus, 2005, 2007; Jackson, 2018; Kelly, 2002; Marotta \& Behrmann, 2004; Romdenh-Romluc, 2007; Rietveld, 2013). More recent studies have also documented cases involving both similar visual agnosia and preserved motor capacity (Farah, 2004, 13; Milner \& Goodale, 2006; for a comparison of Schneider's case with Milner and Goodale's subject, see Kelly, 2002). Further, Schneider's compensatory performances (e.g., motor "tracing" of visual figures) have more recently been described in other subjects with similar impairments (Farah, 2004, 21-22; Marotta \& Behrmann, 2004, 635).

Merleau-Ponty analyzes Gelb and Goldstein's (1920) initial diagnosis of Schneider's "psychic blindness," but he also acknowledges that they later expanded it to include a "blindness for forms" (Gestalten), deficiency of "the simultaneous intuition of wholes," and incapacity to adopt a "categorial attitude" (see MerleauPonty, 1963, 64-65, 71; 2012, 105; 2020a, 101/141, 116/157). Merleau-Ponty $(2012,116)$ is sympathetic with this development and wishes to elaborate further, specifically aiming for a more accurate understanding of the relationship between pointing and grasping, visually representing and touching, which Gelb and Goldstein originally interpreted as an opposition. On one hand, MerleauPonty acknowledges that Schneider's impairments were predominantly perceptual and visual. This conviction was supported by the presumed localization of the lesion in the occipital region $(1963,70)$. More importantly, Schneider did not typically recognize objects through vision alone $(2012,115)$; even when he did, it was based on his act of combining certain visual details (e.g., black dots on a die) with a general idea of an object. That is, Schneider's visual perception was not directed toward the essential features of a given object; for example, he did not recognize a "bad circle" in an imperfectly drawn circular figure. (1963, 66). Moreover, a comparison with aphasic patients showed that Schneider performed more poorly during tasks that required visual recognition, but produced better speech, used a much greater variety of expressions, and frequently corrected 
grammar (66). On the other hand, Merleau-Ponty finds Gelb and Goldstein's initial emphasis on the "visual" character of the impairment "debatable" (Merleau-Ponty, 2020a, 101-102/142; cf. 1963, 65; 2012, 116-122). Merleau-Ponty argues that the visual experience is never simply added to the tactile or motor experiences, and therefore cannot simply be subtracted from the patient's total perception $(2012,121 ; 2020 a, 101-102)$. Each of these domains modifies the others, which makes it impossible for only one to have been impaired in Schneider (2012, 118-119, 121; cf. Mooney, 2011, 365). Analogically, we cannot presume that Schneider conserved the capacity for "concrete" movement in the sense of a physiological process while having lost the function of representation, which purportedly guides "abstract" movements. Far from elucidating the difference between grasping and pointing, explanations based on physiological and representationalist accounts obscure this difference (Merleau-Ponty, 2012, 124-126).

As with any neurological disorder, Merleau-Ponty argues that Schneider's disorder was of a "structural" and "systematic character," and could not be explained as the loss of one part of experiential contents (e.g., vision) or behavior (e.g., "abstract" movement) (1963, 64-65). The disorder affects the patient's experience as a whole, although only "through the privileged material of vision" $(2012,128)$. Schneider's modified structure of experience was first evident at the sensorimotor level. Beyond vision, the disorder also influenced motricity (128), the spatiality of tactile givens, and tactile recognition (1963, 65). For example, Schneider could not motorically "take up" a visual form and see it "as embodying a motor project" $(2020 \mathrm{a}, 115 / 156)$. As such, he could not draw according to models, but instead produced reconstructions of objects based on general ideas determined via motor exploration and verbal articulation (2012, 134; for repreductions of Schneider's drawings, see Goldenberg, 2003, 287). Schneider's tactile experiences were altered due to his difficulty "surveying movement from above" (Merleau-Ponty, 2012, 128), which led to "a shrinking of [his] motor field... [thus] limited to the actually tangible objects and to the exclusion of that horizon of possible touching" (119). Schneider was similarly unable to "take up" temporal wholes such as stories or his own past thoughts (523 n78). Beyond that, Schneider suffered from affective disorientations which impacted his sexual behavior (157-160; Steinfeld, 1927). The very structure of erotic perception and experience was altered because the bodies of his potential sexual partners had no particular structure for him and were "all the same" (Merleau-Ponty, 2012, 158). More generally, he perceived all situations in affectively indifferent manner, as neither pleasant nor unpleasant (159). Schneider's impairment therefore did not affect merely his cognition, in a narrow sense, but structurally modified his entire bodily intentionality.

Schneider's disorder was apparently linked to the "visual" dimension at each of these levels, since his experiences were affected by an inability to "survey" (überschauen, dominer) simultaneous wholes, multiplicities, or Gestalten (MerleauPonty, 2012, 138). In addition to its influences on perception, visual/tactile recognition, motricity, and affectivity, the disorder was also found to affect the "sublimation of sensory vision" at the experiential levels "founded" on the sensorimotor level 
(138, 128). Drawing on Benary's (1922) and Hochheimer's (1932) accounts, Merleau-Ponty briefly discusses how Schneider's injury affected the "properly intellectual" levels of his experiences. ${ }^{6}$ On one hand, there was no sign that Schneider's general intelligence had declined (Merleau-Ponty, 2012, 136, 202). The examiner's instructions "have for him an intellectual signification" and the "thought" is not simply missing in him (113). Further, perceptual and linguistic cues were "certainly not devoid of [an] intellectual signification" for Schneider (135). Although he could not perform "abstract" movements under certain conditions, he was still able to recognize that a given movement constituted an adequate response to examiners' instructions for such movement (113). In this regard, Schneider's "power of representations [extended] to abstract movements" (Mooney, 2011, 364-365; similarly, Jackson, 2018, 768; Apostolopoulos, 2019, 43).

Merleau-Ponty also acknowledges that Schneider suffered from disturbances of "memory, intelligence and language" (1963, 65), "symbolic consciousness" (2020a, 116/157), and "symbolic function" or "thought" (2012, 128; 1963, 234 n46). While the "integrity of language" seemed to be conserved in Schneider, Merleau-Ponty asserts that such integrity was "only apparent" (2020a, 116/157). Drawing on the same sources used by Merleau-Ponty, Goldenberg (2003, 290-291) reports that Schneider was first thought to exclusively rely on the literal meanings of words, and therefore was incapable of understanding metaphor, humor, or any conceptual reasoning beyond "automatised verbal associations" (Hochheimer, 1932, 29, 13-14). Similarly, Schneider presumably suffered from a (primary) "acalculia," or the inability to understand basic arithmetical concepts (Goldenberg, 2003, 290). As discussed in greater detail below, Schneider had substantial difficulty with geometrical and arithmetic operations.

Thus, Schneider did not simply lack the capacity for "higher" cognition. His intelligence was conserved at a general level, but impaired in specific respects. To shed light on the relationship between these two facts, I will first explain how Schneider used somewhat "intellectualist" strategies to address the requirements of his environment.

\subsection{Schneider's compensatory performances}

Before scrutinizing how Schneider's “intellectual” impairments were related to his bodily injuries, it is important to clarify that his sensorimotor capacities were not disturbed because he was "missing" parts of the total experience. When considered in isolation, each of his experiential levels appeared disturbed, but they were also uniquely linked to each other. As previously discussed, Schneider's primarily visual impairment spread to tactile recognition and motricity. Nevertheless, he compensated for insufficiencies at one level by supplementing them with capacities that had

\footnotetext{
6 See Merleau-Ponty $(2012,132-137 ; 157-160 ;$ 201-202; 2020a, 56); cf. the commentaries of Goldenberg (2003, 290-291); Marotta and Behrmann (2004, 633); Apostolopoulos (2019, 43-46).
} 
remained partially available at other levels. Schneider was thus able to accomplish tasks that were impossible in isolation by enwrapping one type of experience into the contexts of other types. ${ }^{7}$ As a number of commentators have observed, Schneider actively used various "tricks" (Merleau-Ponty, 2012, 107) and "clever strategies" (Jackson, 2018, 768) to compensate for his praxic and gnosic difficulties. MerleauPonty emphasizes that these were substitutions for original cognitive operations (Merleau-Ponty, 2012, 110; 2020a, 101/142; 2020b, 115). That is, they were compensatory performances, ${ }^{8}$ not restitutions of original experiences (2020a, 116/157, $56 / 94)$; they could "conceal the deficiency rather than make up for it" (107/148). In this regard, the compensations did not eliminate deficiencies, but did equip Schneider with a way to produce cognitive-behavioral substitutions sufficient for the accomplishment of required tasks in some situations $(1963,66,70)$.

Schneider employed three general types of compensation:

1. He was able to accomplish otherwise impossible motor tasks when allowed to use visual anchoring (Merleau-Ponty, 2012, 110-111; 2020a, 116/158; cf. Mooney, $2011,365)$. Although he did not recognize objects by vision alone, "abstract" movements were possible "the moment he [focused] his eyes upon the limb charged with the task" (Merleau-Ponty, 2012, 115). Although both his motor and visual experiences were deficient, remnants of voluntary motricity drew upon (s'appuie sur) what remained of the visual experience $(2012 / 1945,115-116 / 144)$. The ability to visually objectify his own body helped Schneider compensate for its relative disintegration as a praxic motor agent (2020a, 116/158). In other words, Schneider exploited the fact that the visual superstructure of one's relationship to their own body can "conceal [the] collapse" of the praxic infrastructure (107/148).

2. Compensations between the motor and visual experiences also clearly functioned in the opposite direction in Schneider's case. In other words, he used supplementary motor explorations to increase the accuracy of his perceptions, thus accomplishing tasks that were abstracted from the contexts in which they made sense to him despite his sensorimotor deficiencies. More precisely, Schneider used "preparatory movements" (Merleau-Ponty, 2012, 105, 110-111) and "exploratory twitchings" (Tastzuckungen, 2020a, 101-102/142, 88/129) to more precisely localize stimuli and perform "abstract" movements. For example, he would localize a point on his body that was being touched by putting his entire body into motion and progressively refining (dégrossir) the point's location through additional movements (2012, 109/137). He was similarly able to determine the exact position of his limbs (which he initially ignored) through "gradually specified" movements (2020a, 101/141). Whereas healthy subjects have a relatively immediate intuitive access to the spatial positioning of their body, Schneider reconstituted the spatial presence of his body by progressively determining the relationships between the trunk and ground, arm and trunk, and so on $(2012,110)$. Merleau-Ponty likens Schneider's active reestablishment of contact with his own body to the experience of waking from sleep. To wake

\footnotetext{
7 It should be noted that the isolation was often produced through an experimental setting designed by the researchers and was much less of a problem in Schneider's daily life.

8 Merleau-Ponty refers to Goldstein's term Ersatzleistung.
} 
up is to "restore our diacritical and oppositional systems" by more finely structuring the merely "global," "inarticulated" contact with the world that we maintain in sleep (1970, 47, 9). Schneider's body schema was similarly "dormant" (2020a, 101/142) and "indistinct" in immobility, but reactivated and "specified through action" (se précise par l'action; 98/139; transl. modified).

3. Schneider also compensated for his sensorimotor deficiencies by actively constructing meaning via reasoning and intellectual interpretation. He could accomplish otherwise impossible tasks by relying on sedimented cultural structures such as language and arithmetical series, which he used as "scripts" for action (Merleau-Ponty, 2012, 112). Schneider used "sedimented symbolism and expression," "external verbal knowledge," and the "understanding [intelligence] institutionalized in language" to reestablish meaning for a situation that was perceptually and motorically meaningless to him by itself (2020a, 64/103, 116/157-158). This compensatory strategy transformed Schneider's behavior into a meticulous "methodical interpretation" (2012, 135-136). For him, the recognition of spatial and temporal shapes took the form of "a probable conjecture" that was constructed on the basis of "a rational synthesis" of the "abstract signaling" offered by his perception (111). He "built" objects from disparate qualities "by means of inferences," thus "concluding" on their probable meanings "after extended consideration" (Mooney, 2011, 362). Further, he could "deduce" the position and orientation of his body based on local cues, such as the pressure between the ground and his feet (Merleau-Ponty, 2020a, 102/142; 2012, 109). Also, Schneider incrementally reconstituted a drawing by decoding "signs" that hinted at a preexisting concept $(2012,134)$. At all these levels, he formulated quasi-scientific hypotheses, cross-checked the facts (133), and engaged in experimentation (Schilder, 1950, 23). Schneider thus overcame a variety of sensorimotor limitations by analyzing perceptual cues in terms of preestablished meaningful structures, then subsuming the former under the latter with the help of logical procedures. ${ }^{9}$

In contrast to healthy subjects, Schneider extensively relied on the use of outside sources to bring meaning to his perceptions, particularly by drawing on language (2012, 133; cf. Apostolopoulos, 2019, 43-44). In fact, Merleau-Ponty notes that language clearly intervened in each phase of Schneider's visual recognition "by providing possible significations for what [was] actually seen, and the recognition clearly [progressed] by following the connections of language" (2012, 132-133). Similarly, the "translation of the perceived into movement" passed "through the express significations of language" (134). Lacking a sufficient sensorimotor basis for spontaneous action, Schneider required a "plan settled in advance" (136), which again drew upon language and verbal formulations (106; cf. 2020a, 64/103).

In sum, not only did the visual structures enable Schneider to better anchor his motor projects and vice versa, but the preestablished structures and relationships embedded in language also compensated for a relative loss of structure in his sensorimotor field. Schneider used language-embedded significations and relationships that he acquired prior to the injury for the purpose of organizing and stabilizing his

\footnotetext{
9 As I discuss below (Sect. 2.4.), Schneider adopted a similar approach to symbolic cues.
} 
sensorimotor field. While using his motor capacities to enhance his "theoretical" (visual-linguistic) relationship to the environment, he also used this latter knowledge to support his "practical" (sensorimotor) coping.

\subsection{Schneider's pathology is a dedifferentiation, his compensations differentiations}

Based on the above consideration of Schneider's compensatory performances, I argue that he was not simply lacking an organization of "simultaneous wholes" within the sensorimotor experience, as some commentators have assumed (e.g., Carman, 2008, 115-116). His visual givens were "nearly formless patches," not absolutely formless (Merleau-Ponty, 2012, 115; emphasis added). He was able to distinguish cars from people by vision alone (519, n36). Although he could not immediately recognize an experimentally presented visual object, he did recognize that it was dark in color, oblong in shape, and so on (132). While diagnosed with visual agnosia, Schneider paradoxically used vision to compensate for motor deficiencies (see above, 2.2., point 1).

Moreover, I argue that Schneider's impairment cannot be comprehensively understood if it is viewed merely as a split between the capacities for spontaneously "projecting" possible actions onto his surroundings and responding to affordances (Jackson, 2018, 773; cf. Jensen, 2009, 375; Kiverstein \& Rietveld, 2021, 184; Goldstein \& Scheerer, 1964, 8). As Mooney points out (2011, 361, 371, 376), one's relationship to their surroundings is already transformative at the sensorimotor level, as humans always experience projects as particular characteristics of their surroundings, and vice versa. ${ }^{10}$ If Schneider wholly lacked the capacity to "project" his intentions, then he would not have been able to perform the simplest sensorimotor actions.

Schneider was also at least somewhat capable of overcoming a presumed dissociation between reacting and projecting through his compensatory performances. Although certain types of actions were difficult to access because he could not superimpose the field of possible touch over that of actual touch (Merleau-Ponty, $2012,119)$, Schneider was ultimately able to accomplish these by converting possible situations into actual situations (136-137). While he initially ignored the positions of his limbs and could only avail of his body as an "amorphous mass," he did possess a minimal sense of location, which enabled him to "introduce divisions

\footnotetext{
10 Some commentators have built on Merleau-Ponty's remark that the abstract attitude is a matter of a "centrifugal" relationship with the world and a "projection" of one's intentions into it (2012, 114-115; see Jackson 2018, 774; Jensen 2009; Mooney 2011, 366). However, it should be emphasized that Merleau-Ponty also holds that every "projection" is a "taking up" of something given, which means there is no projection without solicitation and vice versa. Thus, "projection" is already involved in perception, as the latter consists in "taking up" a visual structure, for instance, as embodying certain tactile or motor values (cf. Merleau-Ponty 2020a, 115-116/156-157). In Schneider's case, Merleau-Ponty speaks of a "dissociation" between grasping and pointing, not between projecting and taking up (2012, 105-106; referring to Goldstein 1931; cf. Pacherie 2018, 370-371, 373). Moreover, the "projection" is never operated simply "from within" an individual subject (Mooney 2011, 366), but is rather an act of drawing upon historically and culturally established supra-personal structures, such as arithmetical series or language system.
} 
and articulations" into this mass (112). This also enabled a more precise determination of his positioning by moving. When performing "abstract" movements, Schneider knew "how to recognize what [remained] imperfect in his first attempts" and, despite initiating his actions at random, he sorted his movements out based on their relevance to the given task (113).

The progressive character of Schneider's compensation shows that the presumed capacity of "projection" was not completely dissociated from the capacity to take up affordances in his case. Building on remnants of his sensorimotor and intellectual capacities, Schneider coped with situational requirements at least to some degree. Merleau-Ponty eventually writes that Schneider was able to conceal the eclipse of his spontaneity via sedimented symbolism (2020a, 64/103). Impaired capacities were not simply replaced with presumably conserved ones throughout the compensations, as all of Schneider's capacities were affected. If a specific type of sensory input or cognitive processing were entirely missing or dissociated in his experience, Schneider would lack the basis necessary for building any kind of compensations.

Inspired by Goldstein and other gestaltpsychologists, Merleau-Ponty views neural pathology as a "leveling out" of both the bodily organization and world experienced by the organism. A neuropathological disorder is not a "subtraction" (soustraction), lack, or absence, but a "dedifferentiation" (2020b, 123; cf. 1970, 23). As opposed to the loss of particular type of experiential contents or behaviors, a "pathological transformation takes place in the direction of a less differentiated, less organized, more global and more amorphous behavior" (Goldstein, 2000, 44, cited by Merleau-Ponty, 1963, 64). Based on his review of neuroscientific literature of his time, Merleau-Ponty more precisely argues that specific regions of the brain "are not specialized in the reception of certain contents, but rather in the structuration of these latter;" the regions are "the terrain for the exercise of an activity of organization, applied ... to certain type of materials" $(1963,71)$. Since a neural function "is never indifferent to the substrate by which it is achieved" (69), the localization of a lesion determines "the point of principal application of disorders of structure and their preferential distribution" (70). ${ }^{11}$ However, even an isolated cerebral lesion involves, in addition to specific deficiencies, general disorders of cerebral functioning (233 n35) and structural disorders of the whole of behavior (62-63). Correspondingly, Schneider's "unique lesion in the extra-calcarine optic region caused by a piece of shell" (69) not only caused him difficulties related to the "privileged material" of vision, but also structurally modified all his experiences and behaviors.

Consequently, Schneider's pathology was not characterized by the fact that some presumed parts of his experience or behavior were entirely missing or dissociated, but was associated with the qualitative modification of experiences that required additional compensatory procedures. What needs to be examined, then, is the general functional value of these compensations, or the bodily function they replaced following the physical injury. Schneider's case requires a more precise explanation of how sensorimotor and even intellectual capacities can be deficient at each level, yet simultaneously have the power to compensate for deficiencies at other levels.

11 For Merleau-Ponty's general interpretation of cerebral localization, see (1963, 60-93). 
Merleau-Ponty himself argues that Schneider's deficiencies concern a more fundamental disturbance, deeper function than the individual sensorimotor levels of experience, physiological mechanisms, or presumed function of representation (2012, $121,119,139)$. He claims that it concerns bodily intentionality in the sense of a "capacity for motor differentiation of the dynamic body schema," which correlates with "a certain manner of articulating or of structuring the surroundings" (2012, 143, citing Grünbaum, 1930, 397-398; Merleau-Ponty 2012, 117). The relative dissociations and their relationships to the compensatory performances can only be properly understood if the sensorimotor experience is viewed as a structuring process rather than a complex of content- or representation-related states or functions. ${ }^{12}$

What appears to be affected in Schneider is corporeal intentionality in the sense of the capacity to articulate the structure that defines each of the experiential levels. He related to visual and tactile experiences, the tactile field of his body as a whole, the visual field of his surroundings as a whole, and so on, but the structure of those fields was leveled out. In fact, Schneider's perceptual discrimination was deficient. He could feel being touched, but could not distinguish between two points of contact without additional motor exploration (Merleau-Ponty, 2012, 105, 109; cf. Schilder, 1950, 22). Conversely, his compensatory performances aided in the partial reconstruction of the "epistemological structure" of his sensory experience (Merleau-Ponty, 2012, 116) by introducing articulations from other domains. Thus, Schneider's condition was not pathological because he lacked a connection with some parts of his experiences (certain experiential "wholes"), but because he required additional performances to sufficiently articulate those parts. Because his experiences were leveled out and organized only globally, a cross-modal configuration of visual, tactile, motor, and linguistic figures helped him, and a modal isolation caused him difficulty. From a functional perspective, the general value of Schneider's compensatory performances therefore consists in enabling him to more finely organize his sensorimotor field. In order to make sense of the intentional relationships involving various degrees (cf. Merleau-Ponty, 2012, 126), we must first understand the pathology as dedifferentiation, while the compensatory performances should be understood as progressive differentiations, auxiliary structuring processes. In this case, Schneider's quasi-visual deficits in "surveying simultaneous wholes" must be more precisely understood as an impairment of the capacity to dynamically articulate those wholes.

\subsection{Limitations in Schneider's symbol-based cognition}

Just as Merleau-Ponty refuses to consider Schneider's visual and tactile issues as ultimate deficiencies, he refuses such an interpretation for his "properly intellectual" disorders $(2012$, 135). Moreover, he argues that Schneider's case revealed a deficiency that could not be understood exclusively at the sensorimotor or intellectual

\footnotetext{
12 This fact is usually not recognized by Merleau-Ponty's commentators. An exception here is Jensen (2009, 386-387) who nevertheless arrives to this insight at the end of his discussion rather than taking it as a starting point.
} 
levels, but which instead pertained to the junction of physiological and intellectual processes (132). He thereby rejects Goldstein's idea that Schneider had simply lost the categorial attitude, symbolic function, or representation function (123). According to Merleau-Ponty, the disorder lay beneath intelligence understood as "an anonymous function or a categorial operation;" rather, it pertained to Schneider's existence as specifically modified by the physical injury (136). Exactly as a neuropathological disorder is best understood as a dedifferentiation rather than a subtraction, a "higher" function such as the use of language is not simply the addition of another capacity to a "lower" sensorimotor capacity, but is in fact an "underpinning" of the latter (reprise en sous ouvre; 2020b, 123). For Merleau-Ponty, the cognitive processes that are activated via symbolic systems such as language are a "reiteration at a higher power of [the] process of articulation" or structuration, which we find in the sensorimotor experience (123). Merleau-Ponty thereby argues that articulated thinking is not a construction built on top of embodied experiences, but a "differentiation of what is polymorphic" in them $(1959,179) .{ }^{13}$ These indications enable a more precise determination of how Schneider's physical injury affected his higher cognition, even beyond what Merleau-Ponty explicitly presents in the Phenomenology of Perception.

Above all, Merleau-Ponty rejects intellectualist and ontologically objectivist ideas regarding the objects of "higher-order" cognition, such as mathematical entities. While Gurwitsch $(2009,60)$ claims that "it is a matter of indifference how among the diverse manners the triangle can be drawn," Merleau-Ponty argues that it is only below a certain threshold, and not absolutely, that geometrical or algebraic objects are independent of how they appear. For example, the sum of angles of a triangle is a geometrical property that becomes accessible to the geometer by constructing appropriate auxiliary lines (2012, 403-408; based on Wertheimer, 1938, 279-280). Similarly, one gains access to the algebraic properties of numbers expressed by Gauss' formula $(n \div 2) \times(n+1)$ by structuring a linear numerical series so that its members form pairs of the same value (Merleau-Ponty, 1973, 119, 125-126; based on Wertheimer, 2020, 108-142). Merleau-Ponty therefore holds that we genuinely think in mathematics (and that there is a development in the discipline of mathematics) only by changing the way in which the relatively general mathematical structures inherited from tradition are concretely structured in our field of experience. Geometric and algebraic understanding results from a specific exploration of the phenomenal field correlative to a given geometric space or algebraic series.

Schneider's intellectual cognition was deficient precisely in this capacity for structurally transforming the phenomenal field based on available acquisitions. For example, Schneider understood the nature of visual shapes such as a triangle and a square and also comprehended the relationship between them as linguistic significations. However, he could not ascertain that "every (right isosceles) triangle can serve to construct a square with four times the surface area" because such a construction potentially "demands that the given triangles be assembled differently," by

\footnotetext{
13 Merleau-Ponty clearly elaborates here on his early interpretation of the relationships between physical, vital, and human orders (see 1963, 129-184).
} 
being rotated (Merleau-Ponty, 2012, 133; cf. Benary, 1922, 253-256; Hass, 2008, 82). Because Schneider's phenomenal field had lost its "plasticity" (Merleau-Ponty, 2012 , 113), he could only employ a relatively limited range of intentions to appropriately reorganize it; conversely, elements of the perceptual field only evoked a relatively limited range of intentions to act. For Schneider, like for everyone else, the position of a geometric object within the phenomenal field makes some properties evident while eliminating the possibility to directly comprehend others. However, patients with problems similar to Schneider's cannot access geometrical properties beyond those which are evident from the geometric structures as factually presented, because such an insight requires a transformation of the phenomenal structure of the geometric object. ${ }^{14}$

Similarly, Schneider was capable of adding, subtracting, multiplying, and dividing, but only "with regard to objects placed in front of him" (Merleau-Ponty, 2012, 135). He solved more abstract or purely arithmetical problems "without any intuition of numbers;" that is, only through "manual operations" such as finger-counting or the general "manipulation of signs" or other "fulcra" $(150 ; 1963,67)$. For instance, Schneider was able to conclude that 7 was greater than 4 , but only because it came "after" during recitation. He did not understand that "doubling half" of a given number produced the same number even though he could perform an arithmetical operation that led him to a correct result (Hochheimer, 1932, 227, 240; Merleau-Ponty, 2012, 135). Consequently, Schneider's "number blindness" cannot be explained as a loss of the category or concept of the number (Merleau-Ponty, 2012, 135-136; cf. Benary, 1922, 215-244). Merleau-Ponty argues that even healthy subjects do not require a specific mathematical understanding of the number to perform ordinary arithmetical operations, but can instead follow sedimented arithmetical structures as "kinetic melodies." Schneider's primary acalculia is evidence that the number does not constitute a pure concept that individuals must therefore understand fully or not at all, but is rather a structure that "includes the more and the less" and is therefore organized according to potentially very different degrees of complexity (Merleau-Ponty, 2012, 135). For Schneider, this number-structure was evidently leveled out; he was capable of numeration (135), but not of contracting the processes of structuration of numerical series into the evidence expressed by formulas such as $(7>4)$ or $(2 \times(n \div 2)=n)$. As Merleau-Ponty argues in the Prose of the World (1973, 104-107), such formulas correlate to more specific ways of organizing arithmetical or algebraic numerical series, and must be produced via a structuration of a superior order.

Schneider had to compensate for his incapacity to produce such a structuration by performing arithmetical operations using fixed terms that were comparatively less complex than what was required by the task. Structurally, the actual arithmetical operation played the function of a "preparatory movement" that Schneider employed in the sensorimotor domain; it was an additional exploration that changed the articulation of a given phenomenal structure (i.e., an intentional object such as an

${ }^{14}$ As I discuss below (Sect. 3.3.), patients with Gerstmann's syndrome are faced with the same type of difficulty. 
arithmetical relationship), which was leveled out for him. He therefore had to replace the "simultaneous" grasp of any arithmetical structure beyond the established arithmetical series he had retained, by a successive ${ }^{15}$ operation of structuration, which remained situated at the basic level of that series and relied on perceptual figures such as his fingers, linguistic-numerical series, or other objects that served as structural fulcra for his operations.

Observations on Schneider's mathematical cognition can be further clarified using Merleau-Ponty's notes on his linguistic limitations, which are analogical in several respects (cf. Apostolopoulos, 2019, 40-46; Baldwin, 2007, 96-98). Schneider was still able to use language; his words were organized through their senses, while his vocabulary and syntax appeared intact (Merleau-Ponty, 2012, 201-202). However, Merleau-Ponty contends that the integrity of language was "only apparent" in Schneider due to his "lack of initiative" in this domain (2020a, 116/157). He never behaved spontaneously when using language, nor did he improvise linguistically or formulate new metaphors; he hardly spoke unless questioned, only asked stereotypical question, and never used language to express possible situations (2012, 202; 2020a, 116/157). Language had "lost its productivity" for him (2020a, $107 / 148)$, in which case "the 'life' of language" was "altered" $(2012,201)$. Schneider's sense of words was "somehow congealed" in a "sort of evidentness and selfsufficiency" (202). "Spontaneous language" normally works as "an instrument of action," but this had been diminished to an "automatic language" in Schneider, or merely "a means of disinterested denomination" (180; cf. 1963, 64).

Schneider did not understand simple analogies or metaphors (e.g., the "leg of a chair"); he could only grasp links between the elements involved in a given metaphor by drawing meaningful relationships from the constituted language and then making the link explicit through a conceptual analysis (2012, 129-130). In order to acquire an approximative substitution of an innovative linguistic understanding of the world, he therefore needed to perform the successive steps of a syllogistic operation between terms that had remained fixed in their significations. Schneider's compensatory procedures at the level of linguistic cognition were thus identical to his strategies at other levels (e.g., successively performing an entire arithmetical operation as a substitute for arithmetical cognition, or performing preparatory movements as a substitute for visual perception). Schneider never really concretized the structure of his visual, arithmetical, or linguistic situation in a productive way, but instead largely relied on manipulating fixed terms of the structures that he had retained. For this reason, Merleau-Ponty writes (130) that Schneider's thoughts were no longer "living."

\footnotetext{
15 This procedure was employed by Schneider also in the sensorimotor domain; see Merleau-Ponty (1963, 65; referring to Goldstein 1927, 665).
} 


\subsection{The role of embodiment in "higher-order" cognition: conclusions from Schneider's case}

As discussed in Sect. 2.1., Schneider was limited in his capacity to "take up" visual figures as embodying a motor project. Yet, Merleau-Ponty points out that for Schneider, words were not the motive of a taking up either (135). He could not take up speech produced by others, nor could he do so with records of his own thoughts (523 n78). Similarly, his conception of the number was affected "insofar as it presupposes eminently the power of deploying a past in order to go toward a future" (136). To approximately grasp the meaning of the symbolic objects such as words or numbers, Schneider needed to subject them to his "methodical interpretation." Therefore, Schneider's capacity for "taking up" was limited in the domain of the symbolic in exactly the same manner as in the sensorimotor domain.

Merleau-Ponty $(2012,136)$ more specifically argues that one can only understand Schneider's "intellectual, perceptual, and motor disorders simultaneously and without thereby reducing them to each other" by interpreting them as a leveling out of the "structure 'world,' with its double moment of sedimentation and spontaneity" (132; emphasis added). Taking up Husserl's notion of sedimentation, ${ }^{16}$ MerleauPonty views symbolic systems such as language or arithmetical series as cognitive acquisitions that contract previous relational structuration of the environment into specifically organized fields that enable a reactivation and a continuation of the structuring processes (cf. 2020b, 132). The "contracted knowledge is not an inert mass," he points out, and the established structures are not an "absolute acquisition;" rather, they "feed off [one's] present thought at each moment" and offer a sense which is "taken up and transcended" as the point of departure for further cognitive acts $(2012,131-132,136)$. An acquired geometric, algebraic, or linguistic understanding "is only truly acquired if it is taken up in a new movement of thought" (132; emphasis added). Schneider was limited in both mathematical and linguistic cognition because his diminished capacity for motorically differentiating situations affected his ability to take up the acquired symbolic structures and transpose them across environmental variations.

Regarding Schneider's intellectual limitations, the lack of productivity in the symbolic domains is crucial for Merleau-Ponty (see 2020a, 116/157). On his view, the "true integrity of the [symbolic] superstructures presupposes that of the power of construction, and through this that of the [praxic, sensorimotor] infrastructures" (116/157; cf. 107/148). Once the "superstructures" of symbolic systems became deprived of "the movement that stimulated them" (le mouvement qui les a animées), they merely "conceal the deficiency" in Schneider rather than serving as starting points for cognitive operations of a superior order (107/148, 116/157). Schneider's compensatory performances increased the organizational complexity of his experiences, but occurred under the level of complexity already present in the established

\footnotetext{
${ }^{16}$ In Husserl's later works (1989), sedimentation designates the process through which an originally experienced ideal meaning becomes stabilized in language or other symbolic systems and thus communicable across time and space (cf. Blomberg 2019).
} 
symbolic systems. Schneider's "higher-order" cognition was therefore limited insofar as he merely exploited leveled-out structures through increased effort (preparatory movements, methodical interpretations) rather than more complexly organizing the structures that he had acquired from the cultural tradition. The praxic foundation, which enables a restructuration of the symbolic "superstructures," had collapsed in Schneider (2012, 139), and the superstructures were "in the long run suffering from [this] weakening" (2020a, 110/151). Because the symbolic "superstructures" involved in Schneider's cognition were reduced to a set of fixed fulcra, which he manipulated without structural transformation, Merleau-Ponty claims that they were "profoundly different" from what is normal (116/157).

Merleau-Ponty's interpretation of Schneider's case shows that sensorimotor differentiation is not only active in the sensorial (visual, tactile) domains, but also in the symbolic (geometric, arithmetical, linguistic). The dedifferentiation of Schneider's sensorimotor capacities repercussed at the level of higher cognition as deficiencies in both understanding and the active reconfiguration of symbolic systems that were structurally more specific and more complexly organized than the sedimented forms inherited from the tradition (and which Schneider had conserved to some degree). Merleau-Ponty's discussion on Schneider suggests that embodiment is involved in higher cognition as the capacity to engage in the production of comparatively more complex differentiation of any given phenomenal structure, including the structures accessible only through symbolic systems. In this way, MerleauPonty outlines a relational-structural account of the constitutive (non-causal) role of embodiment in higher cognition.

\section{Gerstmann's syndrome}

\subsection{The complex relationship between apraxia and agnosia}

In the preparatory notes for his 1953 lectures, Merleau-Ponty (2020a/2011) elaborates his account of Schneider's case and the link between sensorimotor and intellectual cognition through an analysis of the relationship between apraxias and agnosias. Above all, he refuses all reductive attempts to explain apraxias in terms of agnosias, but equally refuses a reverse explanation (cf. 2020a, 114-117/154-158). He explicitly states that gnosic types of cognition such as visual recognition, language usage, and numeration cannot be reduced to praxic, sensorimotor activities, and vice versa $(155 / 199)$. However, a mere refusal to accept reductive interpretations does not yet lead to an understanding of their positive relationships. As evidenced by both the many regressions in argumentation and tentative character of his notes, MerleauPonty had some difficulty already with the negative part of the issue. However, his preparatory notes indicate that he attempted to take an additional step in his analysis. Merleau-Ponty aimed to elucidate the complex relationship between praxis and gnosis which he discovered through Schneider's case by analyzing a pathological condition known as Gerstmann's syndrome. 
In adults, Gerstmann's syndrome is caused by tissue damage, for example by impaired blood flow (i.e., ischaemic stroke) or other typically localized insult to the left parietal lobe. Such a diagnosis refers to the concomitant presence of four acquired symptoms: finger agnosia, acalculia, left-right disorientation, and agraphia (Rusconi, 2018, 396). These four deficits may vary in severity and can occur in partial combinations, possibly in conjunction with other neurobehavioral symptoms (Mendoza, 2018, 1565). Finger agnosia ${ }^{17}$ was first described by Gerstmann (1924), who also believed it was the most significant of the four symptoms. It can occur in isolation or in association with agnosic, apraxic, and aphasic difficulties. In a recent overview of research related to Gerstmann's syndrome, Rusconi $(2018,398)$ reported that there was no "concrete and testable mechanism that would securely bind together the four symptoms," which has led to persistent debate on whether they actually constitute a syndrome. It is exactly the "assembly of four unlikely or unexpected symptoms" that is "probably the most intriguing (or puzzling) aspect of the syndrome" (Rusconi, 2018, 397-398, referring to Critchley, 1953, 217). Any controversy over the syndrome is therefore not due to a lack of consistency between relevant empirical data, but is primarily rooted in the fact that no one has yet linked the symptoms in a compelling way. Moreover, current empirical research on mathematical cognition suggests that in healthy subjects, there is "a consistent relationship between improvements of finger gnosis and improvements in finger counting, ordinality judgments, and subitizing" (Fabry, 2018, 801).

As Rusconi (2018) explains, suggestions of a "common principle" for the syndrome have ranged from an apraxic defect to latent aphasia, while other proposals have oscillated between "the loss of general or more specific spatial processes, ordering functions, bodily schema, Gestalt processing, and disturbances of construction or aphasic type" (398). From a Merleau-Pontian view, most of these suggestions are reductive in their attempts to explain the difficulty through either a praxic (sensorimotor) or gnosic (representational) deficit. Merleau-Ponty dismisses such approaches and wants to replace them with a novel interpretation of the body as an "ambiguous" being dynamically structuring several different yet connected levels of our relationship to the world. In Merleau-Ponty's original interpretation, which is foreshadowed by his approach to Schneider's case, the body is the site of a layered architecture of praxic operations that are sedimenting into gnosic structures, which then function as starting points for other levels of cognitive operations (e.g., in gestures or speech). In the remainder of this section, I closely discuss Merleau-Ponty's preparatory notes for his course in order to clarify his novel interpretation of the body and the connection between praxic and gnosic relationships to the world that is based on it.

\footnotetext{
17 This refers to the inability to "show a named finger, to name it and move it when asked to, even when the fingers [are] in full sight, and the commands [apply] to the examiner's finger" (Rusconi 2018, 400). Merleau-Ponty (2020a, 119/160) characterizes finger agnosia as a difficulty recognizing, naming, showing, and selecting the fingers of one's own and/or another person's hands. He also observes that subjects have difficulty identifying any errors related to the fingers and a certain lack of freedom in individual finger movements, even if there is nothing wrong with their sensorimotor capacities.
} 


\subsection{Merleau-Ponty's reading of Lange: the role of hand in calculation}

Merleau-Ponty is interested in Gerstmann's syndrome because in this case, finger agnosia and visual orientation difficulties are associated with both calculation deficits and difficulties with "constructional praxia," or the ability to build, draw, and assemble objects (Merleau-Ponty, 2020a, 119/160). Merleau-Ponty believes that such a constellation of cognitive impairments linked to an alteration of one's visualperceptual relation to their own body provides general insight into the complex relationship between embodiment and intellectual cognition. He discusses the syndrome only very briefly in his preparatory notes (see 108, 110, 119-121, 156-157), and only seems to have directly drawn from Lange's (1933) paper on the issue. However, the syndrome plays an important role in the official summary of the course (Merleau-Ponty, 1970, 3-11/11-21). Citing Lange (1933, 607), Merleau-Ponty endorses the idea that Gerstmann's syndrome reveals the hand as the "focal point where the visual, the linguistic, the spatial, the praxical and the constructive seem to converge" (1970, 8-9/18, transl. modified; cf. 2020a, 120/161). The association of the symptoms found in Gerstmann's syndrome indicates an "ambiguous relation between [the] hand and phasia, praxia, visual and constructive gnosia, [and] thought in general" (2020a, 119/160). Building on the idea of convergence suggested by Lange, Merleau-Ponty elaborates his philosophical argument in favor of a strongly positive (constitutive) role of embodiment in higher cognition.

Merleau-Ponty's preparatory notes discuss Lange's (1933) idea that the hand, which is prominently affected in Gerstmann's syndrome, "acts as [a] point of support [point d'appui] for calculation" (2020a, 119/160). Merleau-Ponty rejects Lange's initial suggestion that in Gerstmann's syndrome, acalculia is linked to the subject's "disturbance of direction" when counting, since there are often undisturbed perceptual directions even in subjects with acalculia (Lange, 1933, 608; MerleauPonty, 2020a, 119/160, 156/201; cf. Schilder, 1950, 43). Thus, although visual-perceptual and arithmetical cognition seem related in the context of the syndrome, they cannot be considered directly dependent. More recent investigations have shown that the orientation of calculation is mapped both spatially and linguistically, since it depends on the writing direction used in the subject's language (e.g., French versus Persian; Mayer et al., 1999, 1117; referring to Dehaene, 1992).

Merleau-Ponty (2020a, 120/161) translates several passages from Lange's paper (1933) in his notes, specifically related to two main ideas: cognitive objectification of the hand and the automation of its praxic function. Lange posits that subjects with Gerstmann's syndrome are impaired in the hand as a sufficiently articulated object (gegliederte Gegenstand), and possibly even in other parts of the body below a certain level of discrimination. The impairment thus becomes apparent when the hand must be "taken apart [by the patient] and, as it were, analyzed in its blueprint" (Bauplan) ${ }^{18}$ rather than being used as an "instrument" (Werkzeug) of a praxic relationship with the external environment (Lange, 1933, 601). Patients cannot use the

18 I use Bryan Smyth's translation of Lange's original text (see Merleau-Ponty 2020a, $220 \mathrm{n} 9$ ) since
Merleau-Ponty translates this passage only approximatively. 
hand as a "material for a spiritual activity" in the context of arithmetical operations (Lange, 1933, 608) when it is "dedifferentiated [entdifferenziert]... not as instrument but as object." The second motif Merleau-Ponty (2020a, 120/161) notices in Lange is related to the fact that the praxic function of the hand must be acquired as an "automatism" (Lange, 1933, 608) in order to serve as a point of support for gnosic activities, or to "free itself for other active acquisitions." Patients with finger agnosia would therefore lack "the capacity to change the hand as instrument at any moment into ... a more complete [vervollkommnetes] instrument" by building on its objectification (Lange, 1933, 608).

Merleau-Ponty appreciates the fact that Lange conceptualizes the hand as strictly necessary rather than an optional point of support for cognitive "superstructures," thereby dismissing "overly intellectualistic" interpretations (2020a, 120/161; cf. $110 / 151,121 / 162)$. Lange's interpretation of the relationship between the body as an instrument and point of support for gnosic tasks also corresponds to the mutually irreducible status of praxis and gnosis, as Merleau-Ponty established and applied to Schneider's case in his 1953 course (cf. 116/157-158). However, Merleau-Ponty distinguishes his position from Lange's by adding important specifications related to the hand's "objectification" and "automatization."

\subsection{Merleau-Ponty on the role of the hand in "higher-order" cognition}

Possibly following Lange's indication (1933, 601), Merleau-Ponty notes that the hand "is not knowable as [a] figure on [a] background" in patients with Gerstmann's syndrome (2020a, 119/160). This means that bodily support for gnosic cognitive activities is acquired by converting the body as a perceptual background into a perceptual figure. Yet, the background implied in perceptual praxis corresponds to the structured, synergic unity of organs oriented toward accomplishing praxical tasks in the world, that is, the body schema $(100-101 / 141 ; 2012,103)$. As evidenced by Merleau-Ponty's examples, the hands and limbs generally constitute what could be called "cardinal points" of the body schema (2012, 100-102, 328). He similarly notes that disturbances of the body schema (e.g., phantoms experienced by amputees) primarily concern active parts of the body, which are closely involved in the exploration of space (2020a, 96/137). Merleau-Ponty therefore agrees with Lange in that the hand plays an important role in human orientation in space $(156 / 201)$, but he understands the "instrumental" function of the hand as a body-schematic activity.

The interpretation of the hand-instrument as a body-schematic function makes it possible for Merleau-Ponty to distinguish the "objectified" hand, presumably supporting the "higher-order" cognitive activities, from a physical hand. As Merleau-Ponty points out, individuals who have lost their physical hands usually retain their sense of what is "handy" or manipulable. In such cases, amputees have not conserved the hand as a representation, but as a body-schematic focal point which incorporates significations that were originally articulated through the physiological hand (2020a, 121/161; cf. 88-89/128-130, 96/136-137, 156-157/201; 2012, 84). Conversely, the presence of physical limbs does not guarantee that a subject knows where to find them or how to use them; in autotopoagnosia, a physically present 
limb is "deintegrated" from the subject's body schema and altered in its explorative power (2020a, 95-96/135-136; based on Schilder, 1950, 40). The "possession" of a hand or any other limb, in a fundamental epistemological sense, therefore entails a capacity for initiating and maintaining certain relationships with the world. Moreover, it entails that, once certain relationship is acquired, one can transpose and maintain it with the help of different means of enaction.

Merleau-Ponty observes that if a certain body-schematic function (e.g., orientation in space) does not immediately disappear with the loss of a physical limb, then it must have been taken over by a different organ (e.g., vision or another limb), which uses different structures that are still physically available (2020a, 157/201). This functional transposition is possible only because the body-schematic relationship to the world produces a certain intentional habitualization, which MerleauPonty also describes as "sedimentation" and "acquisition" (157/201). ${ }^{19}$ However, while Lange claims that the hand must be present as a sufficiently articulated objectified instrument, Merleau-Ponty holds that it is involved in thought "only inasmuch as it forms part of the active body and appears in the body schema" (156/201; emphases added) and, more precisely, inasmuch as it involves a sedimentation of practical intentionality that has the potential to place the subject "above empirical deficiencies or failures" (157/201). Thus, the "objectification" of the hand in gnosis does not correspond to its transformation into an objective physiological automatism or readily-available mental representation, but to a fixation of its intentional value and the maintenance of this value across situational variations. What calculation builds on in the hand seems to be the intentional or relational value that the hand makes available to the subject. As the point of support for calculation, the hand corresponds to a transformation of the body as a body-schematic background for sensorimotor exploratory activities into a figure, and thus into a background and starting point for other types of activity.

A number of other Merleau-Ponty's observations confirm this interpretation. He notes that cases of apraxia and agnosia show a process of a "storing [stockage] of practical intentionality" and therefore attest the possibility of a "sedimentation or cumulative history" of praxis, through which "the orientation toward the thing becomes something that can be seen" and thus grasped in a "theoretical" attitude (2020a, 155/199). To Merleau-Ponty, our body's capacity to incorporate such sedimentations is the foundation of a gnosic, visual-contemplative, and eventually symbol-based relationship to the world. Moreover, the possibility of producing a "trace [of praxis] in a visible world" implies that "disturbances are possible at each of these levels [i.e., praxis and gnosis] that don't affect the other," but also that gnosis potentially "substitutes" for praxic deficiencies (155/199). ${ }^{20}$ As a support for calculation, the hand is not defined by its "factual, physical presence" (121/162), but by its "ambiguous," "equivocal" status $(119 / 160 ; 120 / 161)$ as both an "empirical"

\footnotetext{
19 Regarding the notion of sedimentation, see above Sect. 2.5.

${ }^{20}$ Merleau-Ponty also claims that the body schema incorporates not only the relationships between an individual's body and its perceptual environment, but also those between individuals and "socio-historical relations" (2020a, 118/159).
} 
objective structure and one "laden with human signification," that is, incorporating acquisitions of certain intentional relationships with the world (157/201; cf. 121/162).

The hand in this sense, Merleau-Ponty argues, "is necessary for thought" (2020a, 121/162). This does not mean that thought is "contained" in the sensorimotor gestures of the hand, but rather that it is "punctuated" (ponctuer) by the body-schematic activity of the hand and, ultimately, of the whole body (121/162). Correspondingly, the cognitive impairment involved in Gerstmann's syndrome should not be conceived of as a loss of some general function, such as the sense of direction (Lange, 1933) or the capacity for "transformations of mental images" (Mayer et al., 1999, 1107; for discussion, see Rusconi, 2018, 398, 408). Rather, it should be viewed as a loss of structuration of the "space of activity" of the hand at the level of fingers (Merleau-Ponty, 2020a, 119-120/160) and correlatively of the capacity to produce a certain level of phenomenal structuration.

Several aspects of Gerstmann's syndrome that have not been satisfactorily explained so far seem to support Merleau-Ponty's dynamic structural approach. For example, the finger agnosia affects the median fingers more prominently than external ones, and it also concerns toes (Rusconi, 2018, 401); the acalculia concerns either the manipulation of simple numbers or complex ones, and may or may not be associated with language impairment (397; Mayer et al., 1999, 1108-1109); "mental rotation" of spatial "images" gets more difficult with increased angle of rotation (Mayer et al., 1999, 1115); in some cases, the agnosia disappears when the patient is allowed visual control (Rusconi, 2018, 401). These observations suggest that the difficulties involved in the syndrome have a progressive, gradual character, and that their severity correlates with the organizational complexity of the phenomenon involved in the task. The seemingly unrelated gradual aspects of the difficulties are given a consistent rationale if the syndrome is viewed, as Merleau-Ponty suggests, as a decrease of the capacity for phenomenal structuration that first affects the most finely articulated levels and only then the more global ones. ${ }^{21}$

\section{Conclusion}

This "red under my eyes," Merleau-Ponty explains, has a sense in relation, and in contrast to the redness of blood, the redness of a flag, and all other red things (1968a, 131-132). It is less a thing or positive color quality than "a difference between things and colors," a certain "punctuation [ponctuation] in the field of red things" and all things (132). Similarly, expressive gestures or phonemes of a language do not have a sense by themselves, but only thanks to their "diacritical value" and, ultimately,

\footnotetext{
${ }^{21}$ Merleau-Ponty $(1963,74)$ refers to Henri Piéron's idea that a lesion in the occipital-visual area, depending on its severity, systematically destroys visual functioning beginning with its most fragile forms. He makes a similar point regarding the temporary apraxia of sleep, which "dedifferentiates our praxical functions, beginning with the most subtle, the phonetic system, down to the most elementary" such as locomotion $(1970,9 / 18)$. The possibility of visual compensation and the increase of complexity related to spatial rotation also fits into this interpretation (see above, Sects. 2.2, 2.4).
} 
as "placed in relation to a situation which they underline or punctuate" (2000c, 43). Language itself is, for Merleau-Ponty, a "system of differentiations through which the individual articulates his [or her] relation to the world" $(1970,23)$. MerleauPonty's strongest argument on the role of embodiment in "higher-order" cognition is that without the continuous perspectival modulation provided by the body and its mobility, the structural organization of the world becomes disintegrated, and things lose their sense.

As I have shown in section two, this is what happened to Schneider. His bodily impairment did not just eliminate some portions of his experience or specific mental capacities but resulted in a global levelling out of his world. The impairment structurally modified both his "mental space and practical space" (Merleau-Ponty, 2012, 128). However, the functional implications of the impairment remained dynamic for him, and therefore also allowed for cross-modal compensations. On the practical level, the compensations functionally increased the organizational complexity of Schneider's relationship to his situation. On the level of symbol-based cognitive performances, he could similarly cope with linguistic and mathematical challenges by relying on quasi-exploratory compensatory procedures, such as conceptual analyses and logical inferences. In Merleau-Ponty's view, thus, the body "supports" higher cognition insofar as it assures our capacity to dynamically structure our relation to the environment at the level of symbolic systems.

To elaborate this point, I have explored how Schneider's compensations spanned the presumed gap between "doing" (praxis) and "knowing" (gnosis). I have shown that Merleau-Ponty does not simply choose a bottom-up foundational explanation at the expense of a top-down intellectualist account. On the one hand, he describes how Schneider experienced a relative loss of the capacity for dynamic structuration of his environment but could also scaffold his relationship to situations by using symbol-based scripts. On the other hand, however, Merleau-Ponty points out that Schneider's impaired bodily capacity for dynamic structuration of his environment resulted in his inability to approach linguistic and mathematical tasks productively and constructively, which in turn limited his intellectual proficiency.

In section three, I have described how Merleau-Ponty attempts to elaborate this layered account of the role of the body in symbol-based cognition through his analysis of Gerstmann's syndrome. Beyond refusing reductive accounts of the seemingly distinct levels of "doing" and "knowing," Merleau-Ponty now sketches their relation positively from a dynamic, structural-gestaltist point of view. In contrast to Lange, Merleau-Ponty holds that the hand is involved in calculation insofar as it produces a certain cognitive acquisition, not insofar as it is an object. As one of the cardinal points of the body schema, the hand contributes to establishing a certain relationship to the world, which, once acquired, can be enacted by other means than a physical hand. The hand missing in the Gerstmann's syndrome is therefore the hand as a body-schematic agent. Conversely, the body involved in "higher" cognition seems to correspond to an intentional acquisition that serves as a starting point for the structuration of our relationship to the world on the level of phenomenal differentiation correlative to the cultural symbolic systems.

For Merleau-Ponty, the function of our mobility thus extends far beyond the mere capacity of a change of location in the objective space: it is "a means of articulation 
of a universe" (2020a, 111/151; cf. 1970, 5, 8). The body is implicated in cognition even beyond purely pragmatic sensorimotor domain in a relational sense, that is, insofar as it continues to "punctuate" and carry further the structural reorganizations of the relatively stable cognitive acquisitions such as mathematical series or language system. Merleau-Ponty thereby chooses not to view "higher-order" cognition as hierarchically superior regarding sensorimotor cognition. ${ }^{22}$ Rather, it is for him a more specific structuration of what remains yet polymorphic in our relation to the world, which both builds on and overdetermines the more global, sensorimotor relation.

While Merleau-Ponty's discussions of neuropathological cases do not seem to offer a way to push this analysis much further, his emphasis on active taking up, productivity, and "construction" in the domain of linguistically articulated thought strongly resonates with the importance he attributes to the "positive and conquering function" of speech (1970, 20/32; transl. modified; cf. 2020b). As some of his own remarks suggest, thinking further would require focusing on a description of speech as a body-schematic agent, and on showing how the movement of speech is the movement of thought.

Acknowledgements I would like to thank the two anonymous reviewers for their helpful comments. I am also thankful to Raymond Tallis for his interest and critique, and to Sunwoo Lee for her continous support.

Funding Work on this study was supported by the project "The Dynamics of Corporeal Intentionality," Palacký University Olomouc, reg. no. JG_2019_006.

Availability of data and material Not applicable.

Code availability Not applicable.

\section{Declarations}

Conflicts of interest/Competing interests Not applicable.

Open Access This article is licensed under a Creative Commons Attribution 4.0 International License, which permits use, sharing, adaptation, distribution and reproduction in any medium or format, as long as you give appropriate credit to the original author(s) and the source, provide a link to the Creative Commons licence, and indicate if changes were made. The images or other third party material in this article are included in the article's Creative Commons licence, unless indicated otherwise in a credit line to the material. If material is not included in the article's Creative Commons licence and your intended use is not permitted by statutory regulation or exceeds the permitted use, you will need to obtain permission directly from the copyright holder. To view a copy of this licence, visit http://creativecommons.org/licen ses/by/4.0/.

\footnotetext{
${ }^{22}$ In this respect, Merleau-Ponty's occasional use of the concept of "superstructure" is misleading (see above, Sect. 2.5.).
} 


\section{References:}

Apostolopoulos, D. (2019). Merleau-Ponty's Phenomenology of Language. Rowman \& Littlefield International.

Baldwin, T. (2007). Speaking and Spoken Speech. In T. Baldwin (Ed.), Reading Merleau-Ponty (pp. 87-103). Routledge.

Baldwin T. (2013). Language as the Embodiment of Geometry. In R. Jensen \& D. Moran (Eds.), The Phenomenology of Embodied Subjectivity (pp. 285-303). Springer.

Bay, E., Lauenstein, O., \& Cibis, P. (1949). Ein Beitrag zur Frage der Seelenblindheit: Der Fall Schn. von Gelb und Goldstein. Psychiatrie, Neurologie Und Medizinische Psychologie, 1, 73-91.

Benary, W. (1922). Studien zur Untersuchung der Intelligenz bei einem Fall von Seelenblindheit. Psychologische Forschung, 2(1), 209-297.

Berendzen, J. C. (2010). Coping Without Foundations: On Dreyfus's Use of Merleau-Ponty. International Journal of Philosophical Studies, 18(5), 629-649.

Besmer, K. (2007). Merleau-Ponty's Phenomenology: The Problem of Ideal Objects. Continuum.

Blomberg, J. (2019). Interpreting the concept of sedimentation in Husserl's Origin of Geometry. Public Journal of Semiotics, 9(1), 78-94.

Brender, N. M. (2013). Sense-making and symmetry-breaking: Merleau-Ponty, cognitive science, and dynamic systems theory. Symposium, 17(2), 246-270.

Carman, T. (2008). Merleau-Ponty. Routledge.

Cassou-Noguès, P. (1998). Le problème des mathématiques dans la philosophie de Merleau-Ponty. In M. Merleau-Ponty, Notes de cours sur L'Origine de la géométrie de Husserl (pp. 369-404). P.U.F..

Chrisley, R., \& Ziemke, T. (2006). Embodiment. Encyclopedia of Cognitive Science. https://doi.org/10. 1002/0470018860.s00172

Clark, A. (2008). Supersizing the mind: Embodiment, action, and cognitive extension. Oxford University Press.

Critchley, M. (1953). The Parietal Lobes. Hafner.

Cuffari, E. (2012). Gestural sense-making: Hand gestures as intersubjective linguistic enactments. Phenomenology and the Cognitive Sciences, 11(4), 599-622.

Dehaene, S. (1992). Varieties of numerical abilities. Cognition, 44(1-2), 1-42.

Dijkerman, C., \& Lenggenhager, B. (2018). The body and cognition: The relation between body representations and higher level cognitive and social processes. Cortex, 104, 133-139.

Di Paolo, E., \& Thompson, E. (2014). The enactive approach. In L. Shapiro (Ed.), The Routledge handbook of embodied cognition (pp. 86-96). Routledge.

Dreyfus, H. (2002). Intelligence without representation - Merleau-Ponty's critique of mental representation. The relevance of phenomenology to scientific explanation. Phenomenology and the Cognitive Sciences, 1(4), 367-383.

Dreyfus, H. L. (2005). Merleau-Ponty and Recent Cognitive Science. In T. Carman \& M. B. N. Hansen (Eds.), The Cambridge Companion to Merleau-Ponty (pp. 129-50). Cambridge University Press.

Dreyfus, H. L. (2007). Reply to Romdenh-Romluc. In T. Baldwin (Ed.), Reading Merleau-Ponty (pp. 59-69). Routledge.

Fabry, R. E. (2018). Turing redux: Enculturation and computation. Cognitive Systems Research, 52, $793-808$.

Farah, M. (2004). Visual agnosia. MIT Press.

Gallagher, S. (2010). Merleau-Ponty's Phenomenology of Perception. Topoi, 29(2), 183-185.

Gallagher, S. (2014). Cognitive Science. In R. Diprose \& J. Reynolds (Eds.), Merleau-Ponty: Key Concepts (pp. 207-17). Acumen.

Gallagher, S. (2017). Enactivist Interventions: Rethinking the mind. Oxford University Press.

Gallagher, S. (2018a). Building a stronger concept of embodiment. In A. Newen, L. De Bruin, \& S. Gallagher (Eds.), The Oxford handbook of 4E cognition (pp. 353-364). Oxford University Press.

Gallagher, S. (2018b). Rethinking Nature: Phenomenology and a Non-reductionist Cognitive Science. Australasian Philosophical Review, 2(2), 125-137.

Gelb, A., \& Goldstein, K. (1920). Psychologische Analysen hirnpathologischer Fälle. Johann Ambrosius Barth.

Gerstmann, J. (1924). Fingeragnosie. Eine umschriebene Störung der Orientierung am eigenen Körper. Wiener Klinische Wochenschrift, 37, 1010-1012. 
Goldenberg, G. (2003). Goldstein and Gelb's Case Schn.: A classic case in neuropsychology? In Ch. Code, C.-W. Wallesch, Y. Joanette, \& A. R. Lecours (Eds.), Classical Cases in Neuropsychology, II (pp. 281-99). Psychology Press.

Goldstein, K. (1927). Die Lokalisation in der Grosshirnrinde. In von Bethe (Ed.), Handbuch der Normalen und Pathologischen Physiologie, 10, 600-842.

Goldstein, K. (1931). Über Zeigen und Greifen. Nervenartzt, 4, 453-466.

Goldstein, K. (2000). The organism: A holistic approach to biology derived from pathological data in man. Zone Books.

Goldstein, K. \& Scheerer, M. (1964). Abstract and Concrete behaviour: An experimental study with special tests (Vol. 53, no. 2). Northwestern University Reprint of Psychological Monographs, 1941.

Grünbaum, A. A. (1930). Aphasie und Motorik. Zeitschrift Für Die Gesamte Neurologie Und Psychiatrie, 130(1), 385-412.

Gurwitsch, A. (2009). Some Aspects and Developments of Gestalt Psychology. In F. Kersten (Ed.), The Collected Works of Aron Gurwitsch (1901-1973): Volume II: Studies in Phenomenology and Psychology (pp. 1-61). Springer Science \& Business Media.

Hass, L. (2008). Merleau-Ponty's Philosophy. Indiana University Press.

Hass, M., \& Hass, L. (2000). Merleau-Ponty and the Origin of Geometry. In F. Evans (Ed.), Chiasms: Merleau-Ponty's Notion of Flesh (pp. 177-187). SUNY Press.

Hochheimer, W. (1932). Psychologische Analysen hirnpathologischer Fälle. XIII. Analyse eines "Seelenblinden" von der Sprache aus. Ein Beitrag zur Frage nach der Bedeutung der Sprache für das Verhalten zur Umwelt. Psychologische Forschung, XVI, 1-69.

Husserl, E. (1989). The Origin of Geometry. In J. Derrida (Ed.), Introduction to the Origin of Geometry (pp. 155-180). University of Nebraska Press.

Inkpin, A. (2017). Was Merleau-Ponty a 'transcendental' phenomenologist? Continental Philosophy Review, 50(1), 27-47.

Irwin, B. A. (2017). An enactivist account of abstract words: Lessons from Merleau-Ponty. Phenomenology and the Cognitive Sciences, 16(1), 133-153.

Jackson, G. B. (2018). Maurice Merleau-Ponty's concept of motor intentionality: Unifying two kinds of bodily agency. European Journal of Philosophy, 26(2), 763-779.

Jenkinson, J. (2017). Enactive subjectivity as flesh. Phenomenology and the Cognitive Sciences, 16(5), 931-951.

Jensen, R. T. (2009). Motor intentionality and the case of Schneider. Phenomenology and the Cognitive Sciences, 8(3), 371-388.

Jung, R. (1949). Über eine Nachuntersuchung des Falles Schn. von Goldstein und Gelb. Psychiatrie, Neurologie Und Medizinische Psychologie, 1, 353-362.

Kee, H. (2018). Phenomenology and ontology of language and expression: Merleau-Ponty on speaking and spoken speech. Human Studies, 41(3), 415-435.

Kelly, S. D. (2002). Merleau-Ponty on the Body. Ratio, 15(4), 376-391.

Kiverstein, J., \& Rietveld, E. (2021). Scaling-up skilled intentionality to linguistic thought. Synthese, 198(1), 175-194.

Lange, J. (1933). Probleme der fingeragnosie. Zeitschrift Für Die Gesamte Neurologie Und Psychiatrie, $147(1), 594-610$.

Lawlor, L. (2002). The Legacy of Husserl's "Ursprung der Geometrie": The Limits of Phenomenology in Merleau-Ponty and Derrida. In T. Toadvine, \& L. Embree (Eds.), Merleau-Ponty's Reading of Husserl (pp. 201-223). Kluwer Academic Publishers.

Marotta, J. J., \& Behrmann, M. (2004). Patient Schn: Has Goldstein and Gelb's case withstood the test of time? Neuropsychologia, 42(5), 633-638.

Matherne, S. (2018). Merleau-Ponty on abstract thought in mathematics and natural science. European Journal of Philosophy, 26(2), 780-797.

Mayer, E., Martory, M. D., Pegna, A. J., Landis, T., Delavelle, J., \& Annoni, J. M. (1999). A pure case of Gerstmann syndrome with a subangular lesion. Brain, 122(6), 1107-1120.

Mendoza J. E. (2018). Gerstmann's Syndrome. In J. S. Kreutzer, J. DeLuca, \& B. Caplan (Eds.) Encyclopedia of Clinical Neuropsychology. Springer.

Merleau-Ponty, M. (1945). Phénoménologie de la perception. Gallimard.

Merleau-Ponty, M. (1959). Projet "Être et monde." In M. Merleau-Ponty, Projets. Manuscript deposited at the Bibliothèque Nationale de France, NAF 26989, vol. VI.

Merleau-Ponty, M. (1963). Structure of Behavior. Beacon Press.

Merleau-Ponty, M. (1964). Signs. Northwestern University Press. 
Merleau-Ponty, M. (1968a). The Visible and the Invisible. Northwestern University Press.

Merleau-Ponty, M. (1968b). Résumés de cours. Gallimard.

Merleau-Ponty, M. (1970). Themes from the Lectures. Northwestern University Press.

Merleau-Ponty, M. (1973). Prose of the World. Northwestern University Press.

Merleau-Ponty, M. (1995). La Nature. Notes. Cours du Collège de France. Seuil.

Merleau-Ponty, M. (1996). Notes de cours au Collège de France 1958-1959 et 1960-1961. Gallimard.

Merleau-Ponty, M. (2002). Husserl at the Limits of Phenomenology. Northwestern University Press.

Merleau-Ponty, M. (2003). Nature: Course notes from the Collège de France. Northwestern University Press.

Merleau-Ponty, M. (2010). Institution and Passivity: Course Notes from the Collège de France (19541955). Northwestern University Press.

Merleau-Ponty, M. (2011). Le monde sensible et le monde de l'expression. Cours au Collège de France, Notes, 1953. MetisPresses.

Merleau-Ponty, M. (2012). Phenomenology of Perception. Routledge.

Merleau-Ponty, M. (2020a). The Sensible World and the World of Expression: Course Notes from the Collège de France, 1953. Northwestern University Press.

Merleau-Ponty, M. (2020b). Le problème de la parole. MetisPresses.

Merleau-Ponty, M. (2000c). Un inédit de Merleau-Ponty. In M. Merleau-Ponty, Parcours deux 1951-61 (pp. 36-48). Verdier

Milner, D., \& Goodale, M. (2006). The Visual Brain in Action. Oxford University Press.

Mooney, T. (2011). Plasticity, motor intentionality and concrete movement in Merleau-Ponty. Continental Philosophy Review, 44(4), 359-381.

Morris, D. (2016). Measurement as transcendental-empirical écart: Merleau-Ponty on deep temporality. Continental Philosophy Review, 50(1), 49-64.

Muller, R. M. (2021). Merleau-Ponty and the radical sciences of mind. Synthese, 198, 2243-2277.

Pacherie, E. (2018). Motor intentionality. In A. Newen, L. De Bruin, \& S. Gallagher (Eds.), The Oxford handbook of $4 E$ cognition (pp. 369-87). Oxford University Press.

Pollard, C. (2014). Merleau-Ponty and embodied cognitive science. Discipline Filosofiche, 24(2), 67-90.

Reynolds, J. (2017). Merleau-Ponty's Gordian knot: Transcendental phenomenology, science, and naturalism. Continental Philosophy Review, 50(1), 81-104.

Rietveld, E. (2013). Affordances and Unreflective Freedom. In R. Jensen \& D. Moran (Eds.) The Phenomenology of Embodied Subjectivity (pp. 21-42). Springer.

Robert, F. (2000). Fondement et fondation. Chiasmi International, 2, 351-372.

Romdenh-Romluc, K. (2007). Merleau-Ponty and the power to reckon with the possible. In T. Baldwin (Ed.), Reading Merleau-Ponty: On Phenomenology of Perception (pp. 44-58). Routledge.

Romdenh-Romluc, K. (2011). Merleau-Ponty and Phenomenology of Perception. Routledge.

Romdenh-Romluc, K. (2012). Thought in action. In D. Zahavi (Ed.), Oxford Handbook of Phenomenology (pp. 198-215). Oxford University Press.

Romdenh-Romluc, K. (2018). Science in Merleau-Ponty's phenomenology: From the early work to the later philosophy. In D. Zahavi (Ed.), Oxford Handbook of the History of Phenomenology (pp. 340359). Oxford University Press.

Rusconi, E. (2018). Gerstmann syndrome: historic and current perspectives. In G. Vallar \& H. B. Coslett (Eds.), Handbook of Clinical Neurology, Vol. 151 (pp. 395-411). Elsevier.

Schilder, P. (1950). The Image and Appearance of the Human Body. Routledge.

Shapiro, L. (2019). Embodied cognition. Routledge.

Sheredos, B. (2017). Merleau-Ponty's immanent critique of gestalt theory. Human Studies, 40(2), $191-215$.

Steinfeld, J. (1927). Ein Beitrag zur Analyse der Sexualfunktion. Zeitschrift Für Die Gesamte Neurologie Und Psychiatrie, 107(1), 172-183.

Stawarska, B. (2020). Saussure's Linguistics, Structuralism, and Phenomenology. Springer International Publishing.

Thompson, E. (2007). Mind in life: Biology, phenomenology, and thes ciences of mind. Harvard University Press.

Vallier, R. (2005). Institution: The Significance of Merleau-Ponty's 1954 Course at the Collège de France. Chiasmi International, 7, 281-303.

Varela, F. J., Thompson, E., \& Rosch, E. (2016). The embodied mind: Cognitive science and human experience. MIT press. 
Vörös, S. (2020). Mind Embodied, Mind Bodified. Merleau-Ponty and the Enactive Turn in Mind Sciences. Etudes phénoménologiques - Phenomenological Studies, 4, 91-117.

Wertheimer, M. (1938). The Syllogism and Productive Thinking. In W. D. Ellis (Ed.). A Source Book of Gestalt Psychology (pp. 274-82). Kegan Paul, Trench, Trubner \& Company.

Wertheimer, M. (2020). Productive Thinking. Birkhäuser.

Wilson, R. A. \& Foglia, L. (2017). Embodied cognition. In N. Zalta (Ed.), The Stanford encyclopedia of philosophy (spring 2017).

Publisher's note Springer Nature remains neutral with regard to jurisdictional claims in published maps and institutional affiliations. 